\title{
Analysis on the Development Strategy of Rural Ecotourism in the Times of Internet +
}

\author{
Yuli Wang, Baoding Sun \\ School of Jilin Agricultural University, Changchun, Jilin 130000, China
}

Keywords: Internet; rural; ecotourism; development strategy

\begin{abstract}
In the modern social economic system, rural ecotourism occupies a central position. The innovative development strategy of rural ecotourism is the core business, which is of vital significance for ensuring the environmental protection, high efficiency and scientific nature of rural ecotourism. In the era of economic development Internet +, exploring the effective path of strengthening the development of rural ecotourism has a positive effect on the promotion of rural ecotourism upgrading and development, and is also an important direction for the development of modern rural ecotourism.
\end{abstract}

\section{Introduction}

In the process of developing rural ecotourism management, innovation and development is of great significance. By improving the normative and efficient development path, it is helpful to build a modern tourism management system, improve the comprehensive management efficiency of rural ecotourism, and grasp the direction of tourism development. Rural ecotourism upgrades. With the rapid development of the economy and society, new requirements and challenges have been put forward for the development of traditional rural ecotourism [1]. In the practice of tourism management, there is a widespread problem of lag in concept and lack of innovation in mode, which restricts the improvement of tourism comprehensive management efficiency. An in-depth analysis of the problems existing in rural ecotourism management is a prerequisite for the innovation of the work system. First of all, the rural ecotourism management work lacks institutional optimization design, the rule system is not fully established, and there are still many management loopholes, and there is a problem of insufficient foundation. Secondly, rural ecotourism management does not meet the development requirements of the new era. There is a certain lag in the lack of comprehensive integration of network information technology and social thought. Thirdly, rural ecotourism management lacks strong tourism support, and there is a problem of lack of specialized tourism. These problems need to be further explored and solved.

\section{Analysis on the Value of Optimizing the Development of Rural Ecotourism}

In the tourism industry work system, the development of rural ecotourism occupies a central position and is of vital importance to the overall development. In the practice of carrying out tourism industry work, after years of development, great progress has been made in the development of rural ecotourism, but there are still certain deficiencies. By strengthening the 
development of rural ecotourism and building a modern scientific system, the ecological industry can be upgraded. The comprehensive effect of development meets the needs of the development of the modern tourism industry and adapts to the Internet + era of economic development [2]. In practice, adhering to the traditional model will inevitably lead to backwardness. Based on modern science and technology and information networks, it is necessary to fully recognize the important value of rural ecotourism development and improve the comprehensive efficiency of the tourism industry through optimizing allocation and organizational mobility. From a traditional perspective, the tourism industry work system has been quite perfect, and it has also accumulated rich experience in rural ecotourism development. However, with the rapid development of the economy and society, especially the advent of the Internet+ era, demand is increasingly diversified, and the situation is increasingly Complicated, this is not only an opportunity but also a challenge for the tourism industry. How to adapt to new changes and improve the management efficiency of the tourism industry is the key to improving the development efficiency of the integrated rural ecotourism. Based on this, the search for more optimized rural ecotourism development and tourism industry path is not only the need to adapt to management development, but also the inevitable path to improve the level and requirements of comprehensive services.

\section{The challenges and opportunities of the Internet + era for the development of rural ecotourism}

With the rapid development of China's economy and society, China's economic system has entered the era of Internet + development, which has put forward new requirements and challenges for the traditional structure [3]. Under the Internet+ era, the economic structure has been continuously upgraded and upgraded. By eliminating the backward tourism development model and realizing the optimization of the ecotourism structure, the traditional rural ecotourism development model can no longer meet the requirements of the Internet+ era. With the changes in the structure of tourism industry, the demand for traditional tourism services is decreasing, and higher requirements are put forward for rural eco-tourism. Generally speaking, tourism is required to have higher ecological and natural characteristics, and the development of rural eco-tourism is optimized. Structure, cultivate more high-quality tourism practitioners, and then adapt to the needs of economic development. In this context, no matter for modern education or social rural ecotourism development system, it faces both large impacts and challenges, and it also contains opportunities to build modern rural ecotourism through innovative rural ecotourism development mechanism. The development system can improve the efficiency of rural ecotourism development, promote the continuous optimization of China's tourism economic structure, and realize the transformation of the entire ecotourism industrial system and social structure.

\section{The principle of building a rural ecotourism system under the Internet+ era}

\subsection{Informatization principles}

Building the rural eco-tourism mechanism under the Internet+ era cannot ignore the impact and opportunities brought by the development of contemporary information technology to traditional work. In the practice of rural ecotourism mechanism construction, we should make full use of modern information technology, especially mobile Internet information technology, through the effective integration of resources, through the analysis of big data, etc., effectively understand the needs of ecotourism customers, and enhance the pertinence and effectiveness of work. Sexually and effectively carry out informational transformation, lead the optimization of traditional work systems, improve the efficiency of integrated tourism services, and then adapt to the development needs of 
the Internet + era, and improve the comprehensive quality of rural ecotourism work [4]. It can be said that the optimization of the construction of modern rural eco-tourism mechanism is inseparable from the supporting role of information technology and needs to be further explored.

\subsection{Scientific principles}

Under the background of the Internet + era, rural ecotourism construction is getting rid of the traditional extensive model, improving the refined and scientific level of rural ecotourism development, and improving the scientific level of tourism industry development, which is the basis and guarantee for constructing modern ecotourism pattern. Whether in the implementation of rural ecotourism work or tourism planning, we must make overall planning and overall consideration, combine work practices, improve the scientific nature of rural ecotourism system construction, use modern tourism development concepts to lead traditional development, and improve rural ecotourism development. The comprehensive level, adapt to the needs of modern economic and social development, and play the basic supporting role of rural eco-tourism. In practice, how to seek a scientific tourism development path is an important issue in the face of rural eco-tourism construction. It is necessary to further innovate and promote the continuous optimization of tourism development pattern.

\section{Strategies for the development of rural ecotourism in the Internet+ era}

\subsection{Optimizing the development concept of rural ecotourism}

In the practice of rural ecotourism development, in order to strengthen the effectiveness of tourism development work, we must first start with the concept, construct a modern and scientific work concept, and have a clearer understanding of the development of rural ecotourism from the ideological level. In the practice of rural ecotourism development, some people still adhere to the traditional work concepts and models, do not pay attention to thinking innovation and concept innovation, and fail to recognize the impact of external environmental and economic structural changes on rural ecotourism development work, which restricts the improvement of comprehensive performance [5]. Based on this, the rural ecotourism development staff should strengthen learning, learn advanced concepts and working methods, fully recognize the key significance of optimizing the development of innovative tourism in the overall work, seek an optimized working path, arm the mind with advanced ideas, and find efficient the scientific work path satisfies the development needs of rural ecotourism in the new era and exerts the role of concept innovation.

\subsection{Enhancing the status of ecotourism in the industrial system}

In the practice of rural ecotourism development, there is a widespread lack of attention to ecotourism. In the overall layout of the work, ecotourism development work is often placed at a relatively low level, and it is difficult to play its due role. In this case, the rural ecotourism management personnel should enhance their own ideological cognition and put the ecologically at a better level. Regardless of staffing and resource allocation, they must be inclined and focused. In other ways, improve the level of development work, reduce the resistance in the process of rural ecotourism development, optimize the development work by constructing a modern work pattern, and then lead the work from a higher level to enhance the development effect of the tourism industry [6]. As a development staff, they must also have a clear positioning of themselves, accurately grasp their job responsibilities, and improve their work. 


\subsection{Seeking effective support for the tourism talent team}

With the advent of the Internet+ era, the development of rural ecotourism presents a situation of complexity and specialization. As a rural ecotourism development staff, we must start from our own perspective and improve our work ability. In carrying out development work, it is inseparable from the support of specialized tourism. Only by building a high-quality tourism team can we adapt to the new needs of rural eco-tourism development under the new situation. In the development of rural ecotourism, we must pay attention to the cultivation of compound tourism talents. The development of tourism industry has a strong system and complexity. The ability of personnel to deal with complex situations is relatively high. In the introduction of tourism talents, comprehensive consideration should be made. Introduce a professional tourism team suitable for development, and at the same time strengthen the training of the original work team, cultivate and enhance the business literacy of the staff through various methods, and then adapt to the new development needs of rural eco-tourism innovation [7].

\subsection{Fully relying on modern management mode}

In the practice of rural ecotourism development, in order to seek an effective development path, we must fully utilize the modern tourism management model. With the development of modern society, the traditional tourism industry work and the modern Internet model began to merge, and the traditional work was continuously upgraded. The development of rural eco-tourism as a routine work still has a lot of space for model innovation. As a rural ecotourism development staff, we must strengthen business learning, have a clear understanding of a variety of work models, continue to innovate, improve the accuracy and scientific work, and lead the work to develop. As a rural ecotourism development personnel, it cannot be confined to the traditional work framework. It is necessary to examine the work from a multi-dimensional perspective, grasp the overall development of the tourism industry, be quasi-deterministic about the work content and work direction, and improve the scientific nature of the work.

\subsection{Building a modern big data working mechanism}

In the development of rural ecotourism in the era of big data, we must create a modern working mechanism, rationalize the structure of tourism industry by rationalizing the working relationship, and lay a solid foundation for the application of modern information technology management methods and models [8]. In the practice of traditional rural ecotourism development, there are many factors that restrict the function of modern mode. Therefore, we must find problems in system and mechanism, carry out targeted reform and innovation, optimize the traditional work system, work in the tourism industry, and utilize tourism resources. Explore and innovate, realize the effective flow of tourism resources, enhance the efficiency of ecotourism management, innovate from the institutional level, lay a solid foundation for the utilization and analysis of data resources, adapt to the needs of the "Internet +" era, and enhance the comprehensive level of rural ecotourism development. Adapt to the new trend of work development.

\subsection{Paying attention to the actual situation of the village}

In the development of rural eco-tourism industry, many tourism managers have no scientific understanding in the system construction due to lack of conceptual innovation. Although there are many ideas in the construction of rural eco-tourism system, they are not integrated with the actual situation of the village. Based on this, combined with the actual situation of rural tourism, exploring 
the management system suitable for the development of rural ecotourism is of positive significance for achieving efficient and scientific industrial development goals. When designing the ecotourism system, the staff must not only break through the limitations of traditional thinking, but also ignore the actual situation of tourism.

\section{Conclusion}

In summary, in the practice of rural ecotourism management, concept innovation is an important link. As a tourism practitioner, we must pay full attention to the importance of innovation and development, and start from the perspectives of ideas, thinking, and models to enhance tourism. Develop comprehensive effects and adapt to the needs of the Internet + era. In the next step, the rural ecotourism development staff should work hard to explore, continuously draw on advanced work experience and practices, integrate into work practice, enhance the comprehensive effectiveness of development work, help rural ecotourism development, and achieve leapfrogging goals.

\section{References}

[1] Zhou Feifei. Analysis on the Development Strategy of Rural Ecotourism in Internet + Times. agricultural economy, Vol. 8 (2016) No. 28, p. 46-47.

[2] Chen Wei. Analysis on the Development Strategy of Rural Ecotourism in the Age of "Internet +". Red child, 2018(5):133-134. Vol. 5 (2018) No. 12, p. 133-134.

[3] Liu Lifang.Thoughts on the Combination of New Rural Construction and Rural Ecotourism Development in Yunnan Province. Forest Investigation Planning, 2017(1):114-117. Vol. 1 (2017) No. 32, p. 114-117.

[4] Luo Wei. Research on the Sustainable Development of Rural Tourism under the Ecological Chain of Chongqing. China Agricultural Resources and Regional Planning, Vol. 7 (2017) No.15, p. 195-199.

[5] Zhou Ni. Developing the "Internet + Rural Tourism" service platform to accelerate the acceleration of economic construction in rural areas. Modern Economic Information, Vol. 5 (2018) No. 36, p.481-483.

[6] Wang Xingde. Problems and Suggestions on Rural Ecotourism in China. City Construction Theory Research (Electronic Edition), Vol. 12 (2018) No. 22, p. 3663-3664.

[7] LIU Ming. Research on the Application of Network Platform of "Internet + " Ecological Agriculture Leisure Culture Tourism. Journal of Henan Mechanical and Electrical College, Vol. 3 (2017) No.27, p. 41-44.

[8] Shanna. Internet + background in the development of eco-tourism in the new countryside. Qingdao University of Technology, Vol. 1 (2016) No.1, p. 28-32. 